\title{
Associations between CA19-9 and CA125 levels and human epidermal growth factor receptor 2 overexpression in patients with gastric cancer
}

\author{
HONGBO ZHOU ${ }^{1}$, AILIAN DONG ${ }^{2}$, HUI XIA ${ }^{3}$, GUANGMEI HE $^{4}$ and JIANGHE CUI ${ }^{2}$ \\ Departments of ${ }^{1}$ Oncology, ${ }^{2}$ Gastroenterology, ${ }^{3}$ Clinical Laboratory and ${ }^{4}$ Urinary Surgery, \\ Affiliated Hongqi Hospital of Mudanjiang Medical University, Mudanjiang, Heilongjiang 157011, P.R. China
}

Received April 20, 2017; Accepted November 2, 2017

DOI: $10.3892 / \mathrm{ol} .2018 .8731$

\begin{abstract}
The aim of the present study was to investigate the association between serum carbohydrate antigen (CA)19-9 and CA125 levels, and human epidermal growth factor receptor 2 (HER2) expression in patients with gastric cancer, as well as to identify any correlation between them and the risk of recurrence and metastasis. A total of 256 patients were enrolled in the present study, and 219 patients were followed-up to investigate recurrence and metastasis of gastric cancer. Immunohistochemistry was used to detect HER-2 in gastric adenocarcinoma and paracancerous tissues. The positive rate of CA19-9 and CA125 in stages III/IV was higher compared with that in stages I/II. The positive rate of HER2 in distinct stages of gastric cancer was not statistically different. Serum CA19-9 and CA125 were not associated with the positive expression of HER2. The recurrence and metastasis of CA19-9, CA125 and HER2-positive gastric cancer were increased compared with those experienced by CA19-9, CA125 and HER2-negative patients. Age, stage and preoperative tumor markers were associated with 3-year prognosis of gastric cancer. HER2 [odds ratio $(\mathrm{OR})=2.55$ ] and $\mathrm{CA} 19-9(\mathrm{OR}=1.22)$ were independent prognostic factors in patients with gastric cancer. CA19-9, CA125 and HER2 may be used to predict the recurrence or metastasis of gastric cancer. The combined detection may be able to improve the sensitivity and efficiency of predicting the recurrence or metastasis of gastric cancer. Preoperative positive serum for CA19-9 and CA125 were associated with poor prognosis in patients with gastric cancer. CA19-9 and HER2 were independent prognostic factors of gastric cancer.
\end{abstract}

Correspondence to: Professor Jianghe Cui, Department of Gastroenterology, Affiliated Hongqi Hospital of Mudanjiang Medical University, 5 Tongxiang Road, Mudanjiang, Heilongjiang 157011, P.R. China

E-mail: jianghecui1101@163.com

Key words: gastric cancer, tumor biomarkers, overexpression

\section{Introduction}

Gastric cancer is the fifth most common cancer and the third most common cause of cancer-associated mortality worldwide $(1,2)$. The proportion of locally advanced or metastatic diseases is $\geq 80 \%$ of all patients with gastric cancer in mainland China (3). Carbohydrate antigen (CA)19-9 may be expressed in gastrointestinal cancer cells and is regarded as a gastrointestinal cancer-associated antigen. CA19-9 is also observed in the pancreas, bile duct, salivary gland and other normal epithelial tissue (4). CA19-9 expression is significantly increased in patients with malignant tumors, being markedly increased compared with that in the cases of patients with inflammatory diseases or normal subjects (5). CA19-9 is an effective diagnostic marker, commonly used for digestive tract tumor diagnosis, efficacy evaluation, prognosis and postoperative monitoring (6-8).

In the serum of patients with endometrial carcinoma and digestive tract malignant tumor, the expression level of CA125 can also be detected. Previous clinical trials have demonstrated that serum CA125 may be used as indicators of gastric cancer recurrence; predicting poor prognosis and biological behavior $(9,10)$. Another study revealed that combined determination of serum carcinoembryonic antigen (CEA), CA19-9 and CA72-4 is more sensitive for predicting the risk of recurrence, and for prognosis compared with each protein alone (11). A number of previous studies have investigated the association or correlation between serum biomarkers and the prognosis and rate of recurrence in gastric cancer; however, the association between prognosis and recurrence, serum biomarkers and cellular receptors has not been studied thoroughly. Cellular receptors, including epidermal growth factor receptor 1, human epidermal growth factor receptor 2 (HER2) and transforming growth factor $\beta 1$ have been identified to serve an active function in the progression of intestinal-type gastric adenocarcinoma (12). HER2 has been recognized as a marker for targeting therapy with trastuzumab used to treat metastatic gastric cancer (13). The expression of HER2 is upregulated in $>20 \%$ of patients with metastatic gastric cancer; however, there are currently no serological approaches to predict the expression level of HER2 among patients with locally advanced gastric cancer (14). Conventional serum 
tumor biomarkers, including CA19-9 and CA125, are potentially associated with the detection and prognosis of gastric cancer. The aim of the present study was to investigate the associations between HER2 expression and the level of CA19-9 and CA125, and to correlate these with the prognosis of patients with gastric cancer.

\section{Materials and methods}

Patients and tissue samples. A total of 256 patients from The Affiliated Hongqi Hospital of Mudanjiang Medical University (Mudanjiang, China) were enrolled between January 2014 and December 2014. A total of 157 patients (61.3\%) were male and 99 patients (38.7\%) were female. The median age was 63 years, with a range between 28 and 83 years. Data on patient age, sex and tumor-node-metastasis (TNM) stages were collected from the hospital medical records. The TNM staging system used in this research was adopted from the 2010 publication by the International Union Against Cancer and the American Joint Committee on Cancer (15). All patients included in the study provided written inform consent for participation in the study. The study was approved by the Biomedical Ethical Committee of Affiliated Hongqi Hospital of Mudanjiang Medical University. The preoperative and postoperative gastrointestinal tumor markers were tested. All patients had not received chemotherapy or surgical treatment of gastric cancer prior to surgery. The serum CA19-9 and serum CA125 were performed using a Roche E601 automatic immunoassay analyzer (Roche Diagnostics GmbH, Mannheim, Germany). The tissue samples were collected by endoscopic and intraoperative biopsy.

Immunohistochemistry. An optical microscope (magnification, $\mathrm{x} 200$ ) was used in this study. Gastric cancer tissues were collected from endoscopic and intraoperative biopsy and fixed with $10 \%$ formic acid solution for $2 \mathrm{~h}$ at $60^{\circ} \mathrm{C}$. Subsequently, conventional paraffin embedding was performed, and the sample was sectioned in to $4 \mu \mathrm{m}$ sections. HercepTest Kits (Agilent Technologies, Inc., Santa Clara, CA, USA) was used for HER2 staining. The kits solution was placed into a water bath at $95-99^{\circ} \mathrm{C}$, and incubated in the water for $40 \pm 1 \mathrm{~min}$ according to the manufacturer's protocol.

HER2-positive staining was located in the cell membrane, and the HercepTest modified score was used to evaluate the immunohistochemical staining results (16): (1+) indicates that $>10 \%$ of cells have mild cell membrane staining; (2+) indicates that $>10 \%$ of cells have weak complete or basolateral lateral staining; $(3+)$ means that $>10 \%$ of cells have medium to strong complete or basolateral lateral staining $(0$; meaning negative staining) and (1+) were classed as negative, and (2+) and (3+) were classed as positive.

Follow-up. In the present study, the date of surgery for patients was considered the first diagnosis date and where observations started. The deadline for observation of mortalities was the date of mortality, the deadline for observation of surviving cases was October 31,2016, and the survival time was measured in days. The survival time of the patients with lost follow-up was given as the deadline. Follow-up began in August 2013 and was performed every 3 months with the last visit being October 2016. The follow-up was performed primarily with phone calls. The medication regimens of individual patients were confirmed; and subsequent follow-up appointments were scheduled. Instructions of future treatment were also provided. Patients' overall health, medication status, any minor or major complains and the follow-up statuses were recorded. The status of the patients was recorded using Excel 2010 (Microsoft Corporation, Redmond, WA, USA).

Statistical analysis. Through single factor analysis on the 3-year survival rate of gastric cancer-associated factors, relevant factors were introduced into Cox's multivariate regression model to evaluate the independent prognostic factors of gastric cancer. SPSS 19.0 (IBM Corp., Armonk, NY, USA) was used for statistical analysis. Homogeneity of variance tests and one-way analysis of variance was used with the Student-Newman-Keuls post-hoc method if variance was consistent, or Games-Howell variance method if variance was not consistent. The association between serum indicator and the expression of HER2 was analyzed with Pearson's correlation coefficient test. The survival analyses were conducted according to the Kaplan-Meier method and survival characteristics were compared using log-rank tests. $\mathrm{P}<0.05$ was considered to indicate a statistically significant difference. $\mathrm{P}<0.01$ was considered to indicate a highly statistically significant difference.

\section{Results}

Patient clinicopathological features. Differences between the positive rates of CA19-9, CA125 and HER2 are presented in Table I. The prevalence of serum CA19-9 and CA125 were 25.78 and $24.22 \%$, respectively. The prevalence of HER2 $(2+/ 3+)$ was $16.01 \%$. The prevalence of HER2 $(2+/ 3+)$ between I/II and III/IV TNM stage patients with gastric cancer were significantly different $(\mathrm{P}<0.05)$, with III/IV exhibiting increased rates of positive HER2. The prevalence of HER2 $(2+/ 3+)$ was also associated with tumor differentiation $(\mathrm{P}<0.01)$. No significant association was demonstrated between serum CA19-9, CA125 and HER2 positive rates, and sex or age group ( $P>0.05)$. Serum CA125 also exhibited statistically significant differences in different tumor differentiation and different TNM stage patients $(\mathrm{P}<0.05)$.

Serum CA19-9, CA125 and HER2 positive rate in patients with distinct TNM staging prior to surgery. CA19-9 and CA125 concentration were obtained from clinical examination and HER2 positive rates were obtained from the immunohistochemical analysis of postoperative gastric cancer tissue. A total of 57 cases were classified as stage I, 51 cases were stage II, 142 cases were stage III and 6 cases were stage IV. The concentration of CA19-9 and CA125, and the positive rates of HER 2 were compared with distinct TNM stages. The results are presented in Table II. The results demonstrated in Table II and Fig. 1 revealed the positive expression rates of CA19-9, CA125 and HER2 in patients with different TNM staging gastric cancer.

As can be noted from Table II, the positive rate of CA19-9 and CA125 in stages III and IV was significantly increased compared with that in stages I, and II. In addition, the positive 
Table I. Differences between positive rates of CA19-9, CA125 and HER2 for different clinicopathological features in patients with gastric carcinoma.

\begin{tabular}{|c|c|c|c|c|}
\hline Clinicopathological feature & Total, $\mathrm{n}$ & CA19-9, n (\%) & $\mathrm{CA} 125, \mathrm{n}(\%)$ & HER2 $2+/ 3+, \mathrm{n}(\%)$ \\
\hline \multicolumn{5}{|l|}{ Sex } \\
\hline Male & 157 & $42(26.75)$ & $34(21.66)$ & $22(14.01)$ \\
\hline Female & 99 & $24(24.24)$ & $28(28.28)$ & 19 (19.19) \\
\hline$\chi^{2}$ & & 0.09 & 1.11 & 0.85 \\
\hline P-value & & 0.76 & 0.29 & 0.35 \\
\hline \multicolumn{5}{|l|}{ Age, years } \\
\hline$\leq 60$ & 149 & $36(24.16)$ & $34(22.82)$ & $20(13.42)$ \\
\hline$>60$ & 107 & $30(28.04)$ & $28(26.17)$ & $21(19.63)$ \\
\hline$\chi^{2}$ & & 0.30 & 0.22 & 1.35 \\
\hline P-value & & 0.57 & 0.63 & 0.24 \\
\hline \multicolumn{5}{|l|}{ Tumor differentiation } \\
\hline Well/moderate & 211 & $52(24.64)$ & $45(21.33)$ & $10(4.74)$ \\
\hline Poor & 45 & $14(31.11)$ & $17(37.78)$ & $31(68.89)$ \\
\hline$\chi^{2}$ & & 0.50 & 4.60 & 108.76 \\
\hline P-value & & 0.47 & 0.03 & $<0.0001$ \\
\hline \multicolumn{5}{|l|}{ TNM stage } \\
\hline $\mathrm{I} / \mathrm{II}$ & 108 & $31(28.7)$ & $19(17.6)$ & $9(8.3)$ \\
\hline III/IV & 148 & $35(23.65)$ & $43(29.05)$ & $32(21.62)$ \\
\hline$\chi^{2}$ & & 0.59 & 3.86 & 7.23 \\
\hline P-value & & 0.44 & 0.04 & $<0.001$ \\
\hline
\end{tabular}

CA, carbohydrate antigen; HER2, human epidermal growth factor receptor 2; TNM, tumor-node-metastasis.

Table II. Positive expression rates of CA19-9, CA125 and HER2 in patients with different TNM staging gastric cancer.

\begin{tabular}{lccr}
\hline TNM stage & CA19-9, U/ml & CA125, U/ml & HER2, \% \\
\hline I & $10.9 \pm 88.04$ & $10.21 \pm 1.47$ & 5.21 \\
II & $26.92 \pm 35.18$ & $10.40 \pm 9.8$ & 19.52 \\
III & $32.91 \pm 58.02$ & $12.45 \pm 10.99$ & 40.32 \\
IV & $33.52 \pm 46.46$ & $21.08 \pm 12.3$ & 46.34 \\
t $\chi^{2}$ value & 21.980 & 23.184 & 2.73 \\
P-value & $<0.01$ & $<0.01$ & $<0.01$ \\
\hline
\end{tabular}

a Data are presented as the mean \pm standard deviation. CA, carbohydrate antigen; HER2, human epidermal growth factor receptor 2; TNM, tumor-node-metastasis. $t$, t-test statistic value.

rate of HER2 in different stages of gastric cancer was also statistically different.

Correlation between HER2 and CA19-9, CA125. The correlation of serum CA19-9 and CA125 and the expression of HER2 were analyzed using Pearson's correlation coefficient. The results indicate that there was no correlation between the serum CA19-9/CA125 level and the level of HER2 expression $(\mathrm{P}<0.05)$. The logistic regression results are presented in Table III. The different HER2 expression levels are presented in Fig. 2. The distribution of CA19-9 and CA125 and the expression of HER 2 are presented in Fig. 3.

\section{CA19-9, CA125 and HER2 as prognosis markers in patients with gastric cancer}

Association between CA19-9, CA125 and HER2, and recurrence and metastasis. A total of 219 patients with gastric cancer with follow-up results within 3 years were divided into recurrence/metastasis group and non-recurrence/metastasis group, and the expression of serum tumor markers in the preoperative recurrent group and non-recurrent group were analyzed. There was no significant difference in the results of postoperative recurrence and metastasis between the tumor and metastasis positive group, and negative group. The results are presented in Table IV. Loss of follow-up data of 37 patients was primarily due to the lack of mobile phone connection, a reason why the access to postoperative survival status information was not possible.

As observed from Table IV, CA19-9, CA125 and HER2-positive patients with gastric cancer recurrence and metastasis were increased compared with negative patients. The analyzed results of experimental data were statistically significant $(\mathrm{P}<0.01)$. The HER2 immunohistochemistry scores of gastric cancer tissues are presented in Fig. 2.

Kaplan Meier analysis of recurrence and metastasis of gastric cancer. Survival analysis was performed in patients with stage I, II and III tumors, without disease progression. 
Table III. Association between CA19-9 and CA125, and HER2 positive expression.

\begin{tabular}{|c|c|c|c|c|c|c|c|}
\hline \multirow[b]{2}{*}{ Marker } & \multirow[b]{2}{*}{ HER2 (-) OR } & \multicolumn{2}{|c|}{ HER2 (2+) } & \multicolumn{2}{|c|}{ HER2 (3+) } & \multicolumn{2}{|c|}{ HER2 $(2+/ 3+)$} \\
\hline & & OR $(95 \% \mathrm{CI})$ & P-value ${ }^{a}$ & OR $(95 \% \mathrm{CI})$ & P-value & OR $(95 \% \mathrm{CI})$ & P-value \\
\hline CA19-9 & 1 & $1.36(0.67-2.63)$ & 0.21 & $1.24(0.41-1.76)$ & 0.35 & $1.42(0.85-1.38)$ & 0.25 \\
\hline CA125 & 1 & $1.31(0.22-8.01)$ & 0.79 & $1.85(0.73-1.74)$ & 0.43 & $1.37(0.37-1.87)$ & 0.63 \\
\hline
\end{tabular}

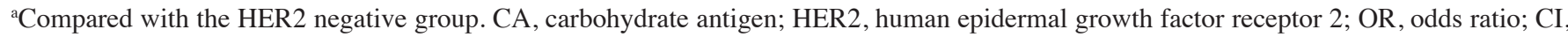
confidence interval.
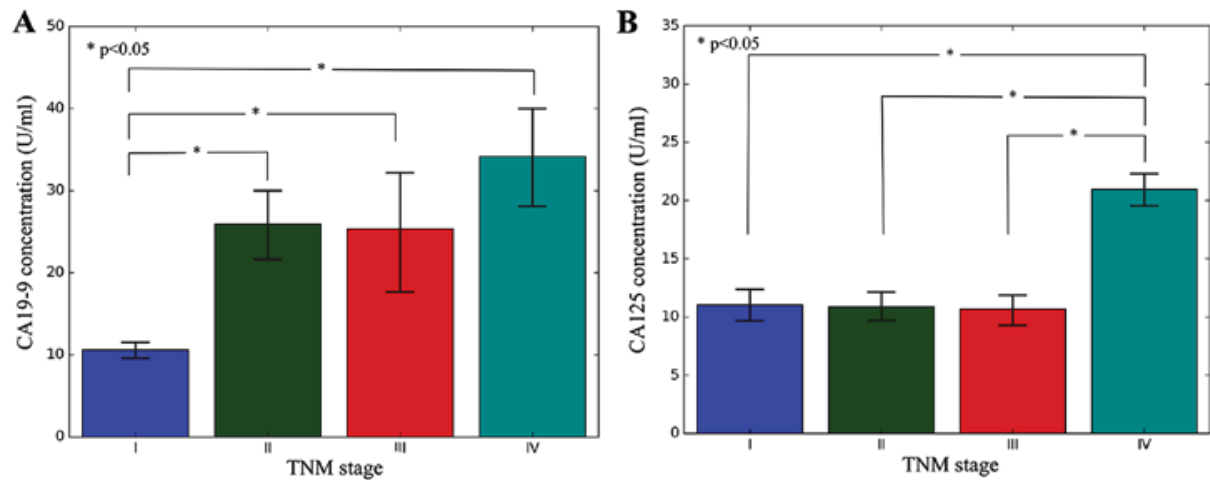

Figure 1. Serum CA19-9 and CA125 in distinct TNM stages of gastric cancer. (A) The serum CA19-9 in stages II, III and IV were significantly increased compared with that in stage I. (B) The serum CA125 in stage IV was significant increased compared with that in stages I, II and III. CA, carbohydrate antigen; TNM, tumor-node-metastasis.

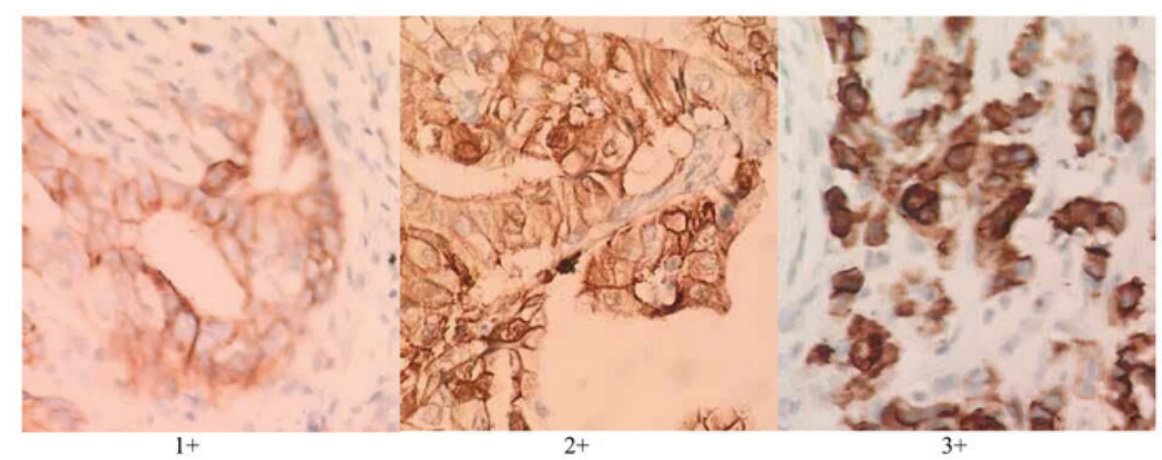

Figure 2. Human epidermal growth factor receptor 2 immunohistochemistry of gastric cancer tissues stratified by scores. (1+) indicates that $>10 \%$ of cells have mild cell membrane staining; (2+) indicates that $>10 \%$ of cells have weak complete or basolateral lateral staining; (3+) means that $>10 \%$ of cells have medium to strong complete or basolateral lateral staining (Magnification, x200).
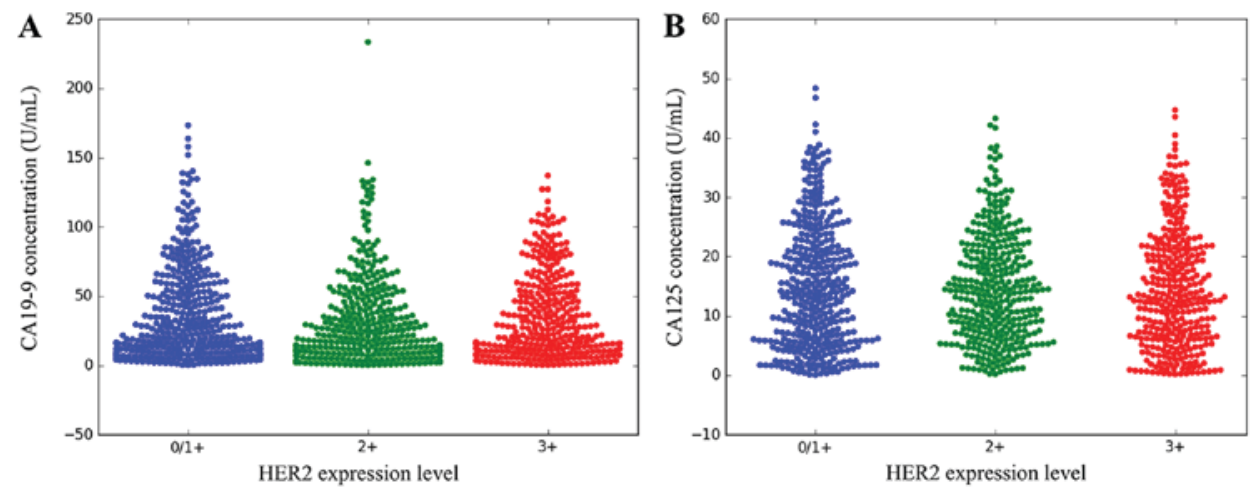

Figure 3. Distribution of serum CA19-9 and CA125 on HER2 expression level. No significant differences between HER2 expression and serum (A) CA19-9 and (B) CA125, were identified. CA, carbohydrate antigen; HER2, human epidermal growth factor receptor 2. 
Table IV. Association between CA19-9, CA125 and HER2, and recurrence and metastasis.

\begin{tabular}{|c|c|c|c|c|c|c|}
\hline \multirow[b]{2}{*}{ Expression } & \multicolumn{2}{|c|}{ CA19-9 } & \multicolumn{2}{|c|}{ CA125 } & \multicolumn{2}{|c|}{ HER2 } \\
\hline & $\begin{array}{l}\text { Recurrence } \\
\text { metastasis }\end{array}$ & $\begin{array}{l}\text { No recurrence } \\
\text { metastasis }\end{array}$ & $\begin{array}{c}\text { Recurrence } \\
\text { metastasis }\end{array}$ & $\begin{array}{c}\text { No recurrence } \\
\text { metastasis }\end{array}$ & $\begin{array}{c}\text { Recurrence } \\
\text { metastasis }\end{array}$ & $\begin{array}{c}\text { No recurrence } \\
\text { metastasis }\end{array}$ \\
\hline Positive & 29 & 8 & 34 & 11 & 32 & 13 \\
\hline Negative & 88 & 94 & 89 & 85 & 84 & 90 \\
\hline$\chi^{2}$ & \multicolumn{2}{|c|}{11.836} & \multicolumn{2}{|c|}{10.378} & \multicolumn{2}{|c|}{6.595} \\
\hline P-value & \multicolumn{2}{|c|}{0.001} & \multicolumn{2}{|c|}{0.001} & \multicolumn{2}{|c|}{0.010} \\
\hline
\end{tabular}

CA, carbohydrate antigen; HER2, human epidermal growth factor receptor 2.

Table V. Recurrence and metastasis time; Log-Rank test results.

\begin{tabular}{llcc}
\hline Tumor markers & \multicolumn{1}{c}{$\chi^{2}$} & df & P-value \\
\hline CA19-9 & 23.919 & 1 & $<0.0001$ \\
CA125 & 10.4055 & 1 & 0.011 \\
HER2 & 15.981 & 1 & 0.002
\end{tabular}

df, degrees of freedom; CA, carbohydrate antigen; HER2, human epidermal growth factor receptor 2 .

The comparisons were performed on the preoperative CA19-9, CA125, HER2-negative and -positive groups. The three indicators were compared separately. The results demonstrated that HER2-positive patients had recurrence and metastasis earlier compared with the negative patients. CA19-9, CA125 and HER2-positive patients without disease progression experiences survival times of 26 months on average (Table V). Negative patients without disease progression experienced survival times of 35 months on average. Gastric cancer recurrence and metastasis time curves are presented in Fig. 4.

Univariate analysis of 3-year survival rate of patients with gastric cancer. The association between sex, age, stage, tumor markers and 3-year survival rate of patients with gastric cancer were used for single factor analysis. The patients $<60$ years of age experienced a higher 3-year survival rate compared with patients $>60$ years of age $(\mathrm{P}<0.05)$. The 3 -year survival rates were significantly different for distinct stages $(\mathrm{P}<0.05)$. The 3-year survival rate of stage I was increased compared with that of stage II and III $(\mathrm{P}<0.05)$. The 3 -year survival rate of patients with positive tumor markers was significantly decreased compared with that of negative patients $(\mathrm{P}<0.05)$. Age, stage and preoperative tumor markers were associated with the 3-year survival rate of gastric cancer $(\mathrm{P}<0.05)$, as shown in Table VI.

Multivariate analysis of 3-year survival rate of patients with gastric cancer. The 3-year cumulative survival rate was used as the dependent variable, and age, sex, CA19-9, CA125 and HER2 were used as independent variables by univariate analysis of statistically significant differences $(\mathrm{P}<0.05)$. Multivariate logistic regression analysis was performed. The results demonstrated that HER2 [odds ratio $(\mathrm{OR})=2.55$ ] and CA19-9 $(\mathrm{OR}=1.22)$ were independent prognostic factors in patients with gastric cancer. The risk of preoperative HER2 positive mortality was 2.55 times higher compared with that of preoperative negative patients. The risk of preoperative CA19-9 positive mortality was 1.22 times higher compared with that of preoperative-negative patients, as shown in Table VII.

\section{Discussion}

In 1979, scientists identified antibodies against colon cancer in mice with colon cancer, and termed them 1165NS199. These antibodies recognized the body's gastrointestinal cancer-associated carbohydrate antigen, and later this antigen was termed the sugar chain antigen 19-9 (4). Previous studies demonstrated that CA 19-9 is associated with the prognosis of patients with gastric cancer, and that it could be used as a prognostic indicator and postoperative monitoring index of gastric cancer (17). Sougioultzis et al (18) conducted a retrospective analysis of 114 cases of gastric cancer, and demonstrated that serum CA 19-9 level is significantly increased in stage IV patients compared with that in stages I, II and III, and preoperative CA19-9 expression is associated with recurrence and metastasis. Marrelli et al (19) monitored the level of CEA and CA19-9 in recurrent and non-recurrence groups following radical gastrectomy, and revealed that the recurrence group was positive for least one tumor marker. Compared with the non-recurrence group, the recurrence group CA19-9 was significantly increased (20). During the follow-up period following surgery, elevated tumor markers indicate a high risk of recurrence (21). The serum levels of CEA, CA72-4 and CA19-9 in 102 patients with gastric cancer were measured by Mihmanli et al (20), in which single factor analysis was performed on recurrence and metastasis. Their results demonstrated that sex, CA72-4 and abnormal CA9-9 levels were associated with a worse prognosis. In addition, multivariate regression analysis was performed on the recurrence and metastasis data, which indicated that CA72-4 and CA19-9 were risk factors for recurrence (22).

CA125 is a glycoprotein that was detected in 1983 as an epithelial ovarian cancer antigen, which binds to the monoclonal antibody OC125 (21). In $80 \%$ of patients with ovarian 
Table VI. Univariate analysis of 3-year survival rate of patients with gastric cancer.

\begin{tabular}{|c|c|c|c|c|}
\hline Characteristic & Total, $\mathrm{n}$ & Mortalities, $\mathrm{n}$ & 3-year cumulative survival rate ${ }^{\mathrm{a}}$ & P-value \\
\hline \multicolumn{5}{|l|}{ Sex } \\
\hline Male & 134 & 67 & $0.501(67 / 134)$ & \multirow[t]{2}{*}{0.725} \\
\hline Female & 85 & 40 & $0.532(45 / 85)$ & \\
\hline \multicolumn{5}{|l|}{ Age, years } \\
\hline$\geq 60$ & 105 & 56 & $0.463(49 / 105)$ & \multirow[t]{2}{*}{0.034} \\
\hline$<60$ & 114 & 49 & $0.572(65 / 114)$ & \\
\hline \multicolumn{5}{|l|}{ TNM stage } \\
\hline I & 42 & 8 & $0.821(34 / 42)$ & \multirow[t]{3}{*}{0.007} \\
\hline II & 54 & 18 & $0.672(36 / 54)$ & \\
\hline III & 123 & 79 & $0.354(44 / 123)$ & \\
\hline \multicolumn{5}{|l|}{ CA19-9 } \\
\hline Negative & 131 & 57 & $0.562(74 / 131)$ & \multirow[t]{2}{*}{0.014} \\
\hline Positive & 88 & 66 & $0.245(22 / 88)$ & \\
\hline \multicolumn{5}{|l|}{ CA125 } \\
\hline Negative & 155 & 62 & $0.603(93 / 155)$ & \multirow[t]{2}{*}{0.007} \\
\hline Positive & 64 & 44 & $0.309(20 / 64)$ & \\
\hline \multicolumn{5}{|l|}{ HER 2} \\
\hline Negative & 123 & 46 & $0.625(77 / 123)$ & \multirow[t]{2}{*}{0.011} \\
\hline Positive & 96 & 63 & $0.345(33 / 96)$ & \\
\hline
\end{tabular}

aValue in brackets, number of mortalities/number of total patients. CA, carbohydrate antigen; HER2, human epidermal growth factor receptor 2; TNM, tumor-node-metastasis.

Table VII. Multivariate analysis of 3-year survival rate of patients with gastric cancer.

\begin{tabular}{|c|c|c|c|c|c|c|}
\hline Characteristic & $\begin{array}{l}\text { Regression } \\
\text { coefficient }\end{array}$ & $\begin{array}{c}\text { SE of partial regression } \\
\text { coefficient }\end{array}$ & P-value & Relative risk & Relative risk & $95 \% \mathrm{CI}$ \\
\hline Age & -0.287 & 0.165 & 0.082 & 0.761 & 0.553 & 1.045 \\
\hline Sex & 0.024 & 0.073 & 0.842 & 1.027 & 0.895 & 1.207 \\
\hline CA19-9 & 0.193 & 0.147 & 0.194 & 1.222 & 0.997 & 1.565 \\
\hline CA125 & 1.176 & 0.191 & 0.383 & 1.190 & 0.828 & 1.712 \\
\hline HER2 & 0.920 & 0.449 & 0.046 & 2.553 & 1.529 & 3.771 \\
\hline
\end{tabular}

CA, carbohydrate antigen; HER2, human epidermal growth factor receptor 2; SE, standard error; CI, confidence interval.
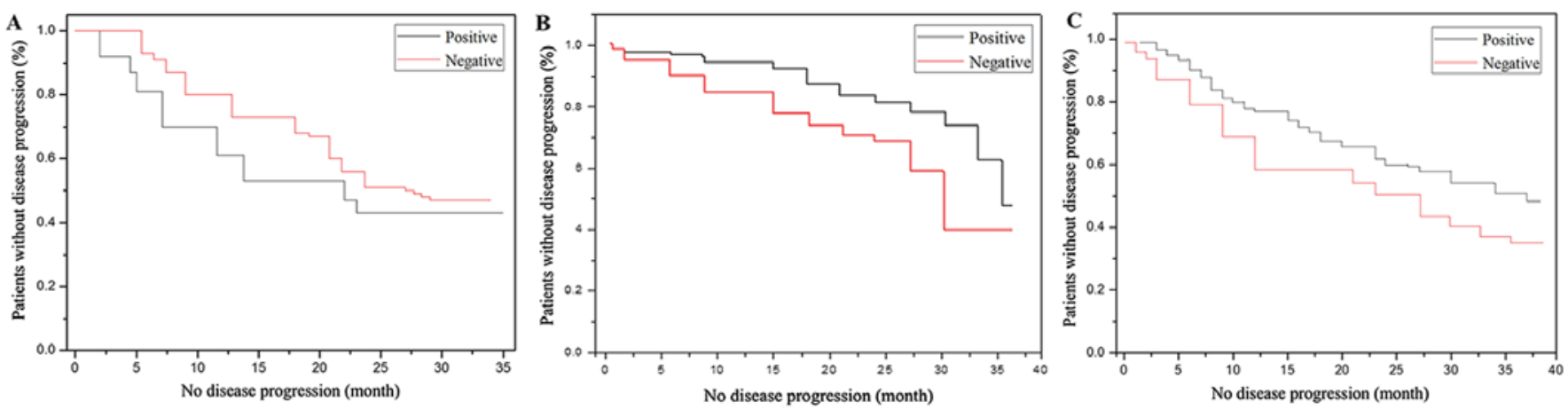

Figure 4. The recurrence and metastasis time curve of gastric cancer (A) Comparison of CA19-9-positive and -negative groups. (B) Comparison of CA125-positive and -negative groups. (C) Comparison of HER2 positive and negative groups. 
cancer, an elevated serum level of CA 125 was detected. Therefore, CA 125 may be used as an indicator of differential diagnosis of ovarian benign and malignant tumors. CA 125 is the most sensitive marker for the detection of epithelial ovarian cancer and is important for diagnosing ovarian cancer, as well as curative effect and prognosis of ovarian cancer (22). CA125 may also be detected in the serum of patients with endometrial and gastrointestinal cancer. Previous clinical trials revealed that serum CA 125 may be used as an indicator to detect the recurrence of gastric cancer, and predict the prognosis and poor biological behavior. The majority of studies on the association between CA 125 and gastric cancer suggest that elevated serum CA 125 is associated with peritoneal metastasis (23-25). Byström et al (26) demonstrated that CA 125 is primarily distributed throughout the ovaries and fallopian tube epithelium, however, it is also identified in the peritoneum, pleura and pericardium of the mesothelial cells. The peritoneal metastasis in those tissues may be a result of peritoneal examination or adhesion, leading to CA 125 antigen content being increased significantly (26).

HER-2 is a member of the human epidermal growth factor receptor family, located on the human chromosome $17 \mathrm{q} 21$. This protein has cell membrane glycoproteins with tyrosine kinase activity, which belongs to the tyrosine kinase type I receptor family (27). The HER-2 gene is a proto-oncogene. Amplification of the gene induces overexpression of the protein in the cell membrane leading to malignant cells. HER-2 is normally only expressed in human fetuses, and is expressed at low levels in a small number of adult tissues that are involved in cell division, growth and reproduction regulation (27). It is associated with cell motility, cell viability enhancement and cancer cell migration (27). HER-2 is overexpressed in a variety of human tumors, such as breast cancer, ovarian cancer, endometrial cancer, lung adenocarcinoma and primary renal cell carcinoma. The overexpression of HER-2 is associated with tumor invasion, metastasis, chemotherapy resistance and poor prognosis. HER-2 has been demonstrated to be involved in the proliferation, differentiation, metastasis and anti-apoptotic effect of cancer cells (28). Overexpression of HER-2 may be indicative of a higher degree of malignancy, rapid progression, sort remission period following chemotherapy, and increased resistance to chemotherapy and endocrine therapy, leading to poor prognosis and decreased survival rates of the patients (29).

There are numerous tumor markers associated with the occurrence and development of gastric cancer. However, due to various factors, including the sensitivity, monitoring methods and monitoring cost, there are not many markers widely used in the clinic. Currently, the most commonly used markers relevant to gastric cancer include CA19-9, CA125 and HER2 (9,26).

In the present study, the association between the aforementioned biomarkers and clinicopathological characteristics of gastric cancer were investigated. Serum tumor markers were negative or significantly decreased in patients with stage I, II and III gastric cancer following radical gastrectomy. Serum tumor marker expression increased alongside progress of the disease, particularly in patients with recurrence and metastasis; in certain cases, expression was double or triple the post-surgery value. The positive rate of
CA 19-9, CA 125 and HER2 in patients with gastric cancer prior to surgery was significantly different from the positive rate of tumor markers in the first 3 months following surgery. The results demonstrated that radical gastrectomy removed the expression of tumor markers in the cancer and the serum tumor markers were significantly decreased or negative.

In conclusion, the present study investigated the association between HER2 expression and CA19-9 and CA125, and explored the association between them and the prognosis of patients with gastric cancer. From the results of the present study, the following conclusions may be drawn: CA19-9, CA125 and HER2 may be used to diagnose the recurrence or metastasis of gastric cancer; the combined detection is able to improve the sensitivity and efficiency of predicting the recurrence or metastasis of gastric cancer; the positive rate of CA19-9 and CA125 in stages III/IV was increased compared with that in stages I/II; pre-surgery positive serum CA19-9 and CA125 was associated with poor prognosis in patients with gastric cancer; and CA19-9 and HER2 were independent prognostic factors for gastric cancer.

\section{Acknowledgements}

Not applicable.

\section{Funding}

No funding was received.

\section{Availability of data and materials}

The datasets used and/or analyzed during the current study are available from the corresponding author on reasonable request.

\section{Authors' contributions}

Conception and design, was the responsibility of $\mathrm{HZ}$ and JC. HX and $\mathrm{GH}$ were responsible for the collection and assembly of data. AD and HX completed data analysis and interpretation and HZ and AD wrote the manuscript. All authors read and approved the final manuscript.

\section{Ethics approval and consent to participate}

The study was approved by the Biomedical Ethical Committee of Affiliated Hongqi Hospital of Mudanjiang Medical University. All patients included in the study provided written inform consent for participation in the study.

\section{Consent for publication}

Patients provided written informed consent for their participation in the present study and the publication of any data.

\section{Competing interests}

The authors declare that they have no competing interests. 


\section{References}

1. Massimo R, Fassan M and Graham DY: Epidemiology of gastric cancer. In: Gastric Cancer. Springer, Cham, pp23-34, 2015

2. Miyashiro I, Hiratsuka M, Sasako M, Sano T, Mizusawa J, Nakamura K, Nashimoto A, Tsuburaya A and Fukushima N; Gastric Cancer Surgical Study Group (GCSSG) in the Japan Clinical Oncology Group (JCOG): High false-negative proportion of intraoperative histological examination as a serious problem for clinical application of sentinel node biopsy for early gastric cancer: Final results of the Japan Clinical Oncology Group multicenter trial JCOG0302. Gastric Cancer 17: 316-323, 2014.

3. Nashimoto A, Akazawa K, Isobe Y, Miyashiro I, Katai H, Kodera Y, Tsujitani S, Seto Y, Furukawa H, Oda I, et al: Gastric cancer treated in 2002 in Japan: 200 annual report of the JGCA nationwide registry. Gastric Cancer 16: 1-27, 2013.

4. Bai LY, Chiu CF, Yang HR and Yang TY: 2230 Palliative gastrectomy does not prolong survival of metastatic gastric cancer patients with both high CEA and high CA19-9 values at diagnosis. Eur J Cancer 51: S410, 2015.

5. Sun Z and Zhang N: Clinical evaluation of CEA, CA19-9, CA72-4 and CA125 in gastric cancer patients with neoadjuvant chemotherapy. World J Surg Oncol 12: 397, 2014.

6. He CZ, Zhang KH, Li Q, Liu XH, Hong Y and Lv NH: Combined use of AFP, CEA, CA125 and CA19-9 improves the sensitivity for the diagnosis of gastric cancer. BMC gastroenterol 13: 87, 2013.

7. Liang Y, Wang W, Fang C, Raj SS, Hu WM, Li QW and Zhou ZW: Clinical significance and diagnostic value of serum CEA, CA19-9 and CA72-4 in patients with gastric cancer. Oncotarget 7: 49565-49573, 2016.

8. Yang AP, Liu J, Lei HY, Zhang QW, Zhao L and Yang GH: CA72-4 combined with CEA, CA125 and CA19-9 improves the sensitivity for the early diagnosis of gastric cancer. Clin Chim Acta 437: 183-186, 2014.

9. Shimada H, Noie T, Ohashi M, Oba K and Takahashi Y: Clinical significance of serum tumor markers for gastric cancer: A systematic review of literature by the Task Force of the Japanese Gastric Cancer Association. Gastric Cancer 17: 26-33, 2014.

10. Kim JH, Jun KH, Jung H, Park IS and Chin HM: Prognostic value of preoperative serum levels of five tumor markers (Carcinoembryonic Antigen,CA19-9, Alpha-fetoprotein, CA72-4, and CA125) in gastric cancer. Hepatogastroenterology 61: 863-869, 2014.

11. Yu J, Zhang S and Zhao B: Differences and correlation of serum CEA, CA19-9 and CA72-4 in gastric cancer. Mol Clin Oncol 4: 441-449, 2016.

12. Docea AO, Mitruţ P, Cernea D, Georgescu CC, Olimid D, Mărgăritescu C and Dumitrescu D: Immunohistochemical expression of EGF, c-erbB-2 and EGFR in intestinal variant of gastric adenocarcinomas. Rom J Morphol Embryol 54: 545-554, 2013.

13. Docea AO, Mitruț P, Grigore D, Pirici D, Călina DC and Gofiță E: Immunohistochemical expression of TGF beta (TGF- $\beta$ ), TGF beta receptor 1 (TGFBR1), and Ki67 in intestinal variant of gastric adenocarcinomas. Rom J Morphol Embryol 53 (3 Suppl): S683-S692, 2012.

14. Liu XH, Sun M, Nie FQ, Ge YB, Zhang EB, Yin DD, Kong R, $\mathrm{Xia} \mathrm{R}, \mathrm{Lu} \mathrm{KH}$, Li JH, et al: Lnc RNA HOTAIR functions as a competing endogenous RNA to regulate HER 2 expression by sponging miR-331-3p in gastric cancer. Mol Cancer 13: 92, 2014.

15. Edge SB and Compton CC: The American Joint Committee on Cancer: The 7th edition of the AJCC cancer staging manual and the future of TNM. Ann Surg Oncol 17: 1471-1474, 2010.
16. Hofmann M, Stoss O, Shi D, Büttner R, van de Vijver M, Kim W, Ochiai A, Rüschoff J and Henkel T: Assessment of a HER2 scoring system for gastric cancer: Results from a validation study. Histopathology 52: 797-805, 2008.

17. Chiu CF, Yang HR, Yang MD, Jeng LB, Yang TY, Sargeant AM, Bai LY. Palliative Gastrectomy Prolongs Survival of Metastatic Gastric Cancer Patients with Normal Preoperative CEA or CA19-9 Values: A Retrospective Cohort Study. Gastroenterol Res Pract 2016:6846027, 2016.

18. Sougioultzis S, Syrios J, Xynos ID, Bovaretos N, Kosmas C, Sarantonis J, Dokou A, Tzivras D, Zografos G, Felekouras E, et al: Palliative gastrectomy and other factors affecting overall survival in stage IV gastric adenocarcinoma patients receiving chemotherapy: A retrospective analysis. Eur J Surg Oncol 37: 312-318, 2011.

19. Marrelli D, De Stefano A, de Manzoni G, Morgagni P, Di Leo A and Roviello F: Prediction of recurrence after radical surgery for gastric cancer: A scoring system obtained from a prospective multicenter study. Ann Surg 241: 247-255, 2005.

20. Mihmanli M, Dilege E, Demir U, Coskun H, Eroglu T and Uysalol MD: The use of tumor markers as predictors of prognosis in gastric cancer. Hepatogastroenterology 51: 1544-1547, 2004.

21. Lordick F and Janjigian YY: Clinical impact of tumour biology in the management of gastroesophageal cancer. Nat Rev Clin Oncol 13: 348-360, 2016.

22. Verlato G, Roviello F, Marchet A, Giacopuzzi S, Marrelli D, Nitti D and de Manzoni G: Indexes of surgical quality in gastric cancer surgery: Experience of an Italian network. Ann Surg Oncol 16: 594-602, 2009.

23. Kim KM, Bilous M, Chu KM, Kim BS, Kim WH, Park YS, Ryu MH, Sheng W, Wang J, Chao Y, et al: Human epidermal growth factor receptor 2 testing in gastric cancer: Recommendations of an Asia-Pacific task force. Asia Pac J Clin Oncol 10: 297-307, 2014.

24. Ieni A, Barresi V, Rigoli L, Caruso RA and Tuccari G: HER2 status in premalignant, early, and advanced neoplastic lesions of the stomach. Dis Markers 2015: 234851, 2015.

25. Luis M, Tavares A, Carvalho LS, Lara-santos L, Araújo A and De mello RA: Personalizing therapies for gastric cancer: Molecular mechanisms and novel targeted therapies. World J Gastroenterol 19: 6383-6397, 2013.

26. Byström P, Berglund A, Nygren P, Wernroth L, Johansson B, Larsson A, Einarsson R and Glimelius B: An explorative study on the clinical utility of baseline and serial serum tumour marker measurements in advanced upper gastrointestinal cancer. Oncol Rep 24: 1645-1652, 2010.

27. Moore RG, McMeekin DS, Brown AK, DiSilvestro P, Miller MC, Allard WJ, Gajewski W, Kurman R, Bast RC Jr and Skates SJ: A novel multiple marker bioassay utilizing HE4 and CA125 for the prediction of ovarian cancer in patients with a pelvic mass. Gynecol Oncol 112: 40-46, 2009.

28. Ishida M, Kagawa S, Shimoyama K, Takehara K, Noma K, Tanabe S, Shirakawa Y, Tazawa H, Kobayashi $\mathrm{H}$ and Fujiwara T: Trastuzumab-based photoimmunotherapy integrated with viral HER 2 transduction inhibits peritoneally disseminated HER2-negative cancer. Mol Cancer Ther 15: 402-411, 2016.

29. Emoto S, Ishigami H, Yamashita H, Yamaguchi H, Kaisaki S and Kitayama J: Clinical significance of CA125 and CA72-4 in gastric cancer with peritoneal dissemination. Gastric Cancer 15: 154-161, 2012. 